\title{
ETIN İŞLENMESİ VE SAKLANMASI İMALAT SEKTÖRÜNÜN FİRMA YOĞUNLAŞMA BAKIŞ AÇISI İLE ANALİZI
}

\section{Kübra ÖNDER ${ }^{1}$ \\ Coşkun PINAR ${ }^{2}$}

\section{ARTICLE INFO}

Article history:

Received 17 Aug 2021

Accepted 5 Oct 2021

\section{JEL classification: \\ D21 \\ D22 \\ D43.}

\section{Keywords:}

Firm Concentration

Market Structure

Meat Processing and Storage

Manufacturing Sector.

\section{MAKALE BİLGISİ}

Makale Geçmişi:

Geliş Tarihi: 17 Ağustos 2021

Kabul Tarihi: 5 Ekim 2021

\section{JEL kodu: \\ D21 \\ D22 \\ D43.}

\author{
Anahtar kelimeler: \\ Firma Yoğunlaşma \\ Pazar Yapısı \\ Etin İşlenmesi ve Saklanması \\ İmalat Sektörü.
}

\begin{abstract}
ÖZET
Et işleme ve saklama sektörü, hayvancılığa dayalı önemli bir sanayi kolu olup, hayvansal hammaddeleri çeşitli işlemlere tabi tutmakta ve hayvansal ürünleri tüketime hazır ürüne dönüştürmektedir. Bu sayede sektör, hayvansal ürünlerin daha uzun soluklu saklanmasina ve tüketilmesine imkân sunmaktadır. Dolayısıyla bu çalışmanın amacı, hayvancılık sektöründe oldukça önemli yere sahip olan etin işlenmesi ve saklanmasl, kümes hayvanların etlerinin işlenmesi ve saklanması ile et ve kümes hayvanları etlerinden üretilen ürünlerin imalatı sektörlerinde faaliyette bulunan firmaların yoğunlaşma düzeyini, rekabet durumunu ve ilgili sektörün piyasa yapısını analiz etmektir. Analizde; sektörde faaliyet gösteren firmaların 20122019 dönemlerine ait net satış rakamlarından yararlanılmış ve firmaların yoğunlaşma düzeyinin hesaplanmasında $k$ firma, Herfindahl-Hirchman, Entropi ve Kapsamlı yoğunlaşma indeksleri kullanılmıştır. Yapılan analiz sonucunda; (i) firma yoğunlaşma düzeyinin düşük, (ii) piyasadaki rekabet düzeyinin yüksek ve (iii) piyasanın tam rekabete yakın veya monopolcü rekabet yapısına sahip olduğu sonucuna ulaşılmıştır.
\end{abstract}

\footnotetext{
${ }^{1}$ Doç. Dr., Burdur Mehmet Akif Ersoy Üniversitesi İktisadi ve İdari Bilimler Fakültesi, İktisat Bölümü, konder@mehmetakif.edu.tr, Orcid: 0000-0003-3537-3635 2 Yüksek Lisans Öğrencisi, Burdur Mehmet Akif Ersoy Üniversitesi, Sosyal Bilimler Enstitüsü, İktisat Anabilim Dalı, coskunpinar@mehmetakif.edu.tr, Orcid: 0000-0001-7271-0472

DOI: $10.53839 /$ aifd.983725
}

\begin{abstract}
Meat processing and storage sector is an important branch of industry which is based on animal husbandry and in which animal raw materials are subjected to various processes and animal products are transformed into ready-to-eat products. In this way, the sector allows the longerterm storage and consumption of animal products. Therefore, the aim of the current study is to analyze the concentration level, competitiveness and market structure of the companies operating in the sectors of meat processing and storage, processing and storage of poultry meat, and the production of products produced from meat and poultry meat, which have a very important place in the livestock sector. In the analysis, the net sales figures of the companies operating in the sector for the period of 2012-2019 were used and kfirms, Herfindahl-Hirchman, Entropy and Comprehensive concentration indexes were used to calculate the concentration level of the companies. As a result of the analysis, it was concluded that (i) the level of firm concentration is low, (ii) the level of competition in the market is high, and (iii) the market has a strong monopolistic competition structure close to perfect competition.
\end{abstract}




\section{GíRIŞ}

Gıda sanayiden bahsedebilmek için sanayi devrimi ve sonrası dönemi ele almak gerekse de geleneksel gıda imalatı ve gıdaların saklanması işlemi insanlık tarihi kadar eskidir. Tüm canlılar gibi insanlar da hayatın devamlılığı için gıdaya öncelikli olarak ihtiyaç duymaktadır. Gıdalar içerisinde yer alan et ve et ürünlerinin tüketimi de insanın ruh ve beden sağlığı için en az diğer gıdalar kadar önemlidir. İnsan sağlığı için olmazsa olmazlardan olan et aynı zamanda gerek üretim miktarı gerek tüketim miktarı gerekse de et ürünlerine ulaşma imkanı bakımından kalkınma göstergelerinden biridir (Ovalı, 2002).

Et sektörü, kırmızı ve kanatlı olmak üzere iki ana çatıda ele almaktadır. Sektör, tarıma dayalı sektörler içinde en yüksek toplam hasılaya sahiptir (Serhat Kalkınma Ajansı [SEKA], 2015: 9). Nitekim Birleşmiş Milletler Gıda ve Tarım Örgütü (FAO) verilerine göre 2019 yılında dünya tarımsal üretim değerinin yaklaşık \%17'si hayvancılık sektörüne aittir (FAO, 2021a). Türkiye'de ise tarım sektöründen elde edilen 277.495 milyon TL'lik üretimin yaklaşık 93.917 milyon TL'si hayvancılık sektöründen elde edilmektedir. $\mathrm{Bu}$ üretim düzeyinin \%65'i (yaklaşık 2,1 milyon ton) kanatlı etten elde edilirken geriye kalan 1,2 milyon tonu ise kırmızı etten sağlanmaktadır (TÜİK, 2021a,b). 2018 yll itibariyle sektörde toplam 1259 girişimci işletme bunulmaktadır. Bu işletmelerden 383'ü etin işlenmesi ve saklanması sektöründe (Nace Rev.2 kodu: 10.11), 89'u kümes hayvanları etlerinin işlenmesi ve saklanması sektöründe (Nace Rev.2 kodu: 10.12) ve 787'si ise et ve kümes hayvanları etlerinden üretilen ürünlerin imalatı (Nace Rev. 2: 10.13) sektöründe faaliyet göstermektedir (TÜİK, 2021c). Ayrıca sektör 36,1 milyar TL ciroya sahip olup, istihdama da büyük katkı sağlamakta ve yaklaşık 48,4 bin kişiyi doğrudan istihdam etmektedir (TÜİK, 2021d,e). Gıda sektöründe istihdam edilen bireylerin yaklaşık \%9,4'ü et sektöründe istihdam edilmesine rağmen sektörün istihdama katkısı bununla da sınırlı kalmamakta (Bölgesel Çevre Merkezi [REC], 2016) ve sektöre ara girdi veya hammadde sağlayan üretici, sektörle bağlantılı esnaf yine sektörle ilişkili yem ve ilaç sanayi ile nakliye ve pazarlama sektörleri ile istihdama dolaylı katkı sağlamaktadır.

Etin insan sağllğı üzerindeki etkisi ve et işleme ve üretim sektörünün ekonomiye sağladığı katkı dikkate alındığında, sektörün rekabet durumunun ve yoğunlaşma düzeyinin analizi oldukça önem arz etmektedir. $\mathrm{Bu}$ bağlamda çalışmanın amacı, sektörün piyasa yapısını ortaya koymak, sektörde faaliyet gösteren firmaların yoğunlaşma düzeyini hesaplamak ve sektörün rekabet durumunu analiz etmektir.

$\mathrm{Bu}$ amaç doğrultusunda, çalışmada ilk olarak et sektörünün Türkiye ekonomisindeki yeri ele alınmıştır. Ardından, analiz konusuna yönelik literatür detaylı olarak tanıtılmış ve çalışmada kullanılan materyal ile yöntem hakkında bilgi verilmiştir. Çalışmada son olarak model tahmin sonuçlarına yer verilmiş ve ulaşılan ampirik sonuçlar tartışılmıştır.

\section{ET SEKTÖRÜNÜN TÜRKIYE EKONOMISINDEKI YERİ}

Türkiye'nin hemen hemen her bölgesinde küçük aile işletmeleri ile başlayan et üretimi günümüzde teknolojik gelişmelere paralel olarak profesyonelleşme eğilimindedir. Her ne kadar geleneksel üretim yapan kobilerin sektör içinde ağırlığı azımsanmayacak seviyelerde olsa da, modern kesim ve saklama koşullarına sahip işletmeler tarafından hijyenik koşullarda üretim gerçekleştirilmektedir.

1952 yılına kadar günübirlik kesim, satış ve stoksuz sistem ile faaliyet gösteren et sanayi, Et ve Balık Kurumu'nun (EBK) kurulması ile birlikte modern tesislere kavuşmuştur. 1982 yılında özel sektöre et kombinası kurma yetkisinin verilmesi ile de özel sektör sisteme dahil edilmiştir (Önder, 2018). Endüstrideki gelişmeler bunlarla da sinırlı kalmamış ve zaman içinde sektörde yaşanan gelişmelerin ve iyileşmelerin bir sonucu olarak sektör alt sektörlere ayrılmıştır. Şimdilerde et ve et ürünleri sektörü; (i) etin işlenmesi ve saklanması, (ii) kümes hayvanları etlerinin işlenmesi ve saklanması ile (iii) et ve kümes hayvanları etlerinden üretilen ürünlerin imalatı olmak üzere 
üç alt sektörde faaliyet göstermektedir (Bölgesel Çevre Merkezi [REC], 2016). Bu sektörlerde 2012 yılı itibariyle halihazırda 1161 kesimhane bulunmaktadır. Bunların 1102'si kımızl et kesimhanesi, 59 tanesi kanatlı et kesimhanesi ve 2 tanesi ise diğer kesimhanelerdendir (Tarım ve Orman Bakanlığı, 2012). Kesimhanelerin toplam kurulu kapasitesi yaklaşı 380,6 milyon baş/gün olup, toplam üretim miktarları 2019 yılı için yaklaşık 3,68 milyon tondur (OECD, 2021a). Üretim miktarı ile Türkiye, dünyada önemli bir yere sahiptir. Nitekim, kanatlı eti ve ürünleri üretiminde (GTP 0207) (2,13 milyon ton) dünyada onbirinci sırada yer almaktadır. Bu durum kırmızı et üretiminde de farklılaşmamakta ve Türkiye, koyun eti üretiminde (3,8 bin ton) dördüncü, sığır eti üretiminde (1,08 milyon ton) onikinci ve keçi eti üretiminde $(7,2$ bin ton $)$ ise 14 . sirada bulunmaktadır (FAO, 2021b).

Türkiye'nin et üretim miktarındaki artışa paralel olarak et tüketim miktarında da artış yaşanmıştır. Et tüketim miktarı, 2019 yılında, 1,66 milyon tonu kırmızı et 1,68 milyon tonu kanatlı eti olmak üzere toplamda 3,34 milyon tona ulaşmıştır (Tablo 1). Tüketimdeki bu gelişme kişi başına düşen et tüketim miktarını da olumlu etkilemiş ve son on yıllık süreçte kişi başına düşen et tüketim miktarı \%30,7 artarak 2019 yılında (domuz eti hariç) ortalama 10,02 kg'a yükselmiştir. Bu tüketim değeri ile Türkiye, dünya ortalamasının $(7,55 \mathrm{~kg})$ üstünde yer almaktadır (OECD, 2021b).

Tablo 1. Türkiye Et Üretim ve Tüketim Miktarı (Ton)
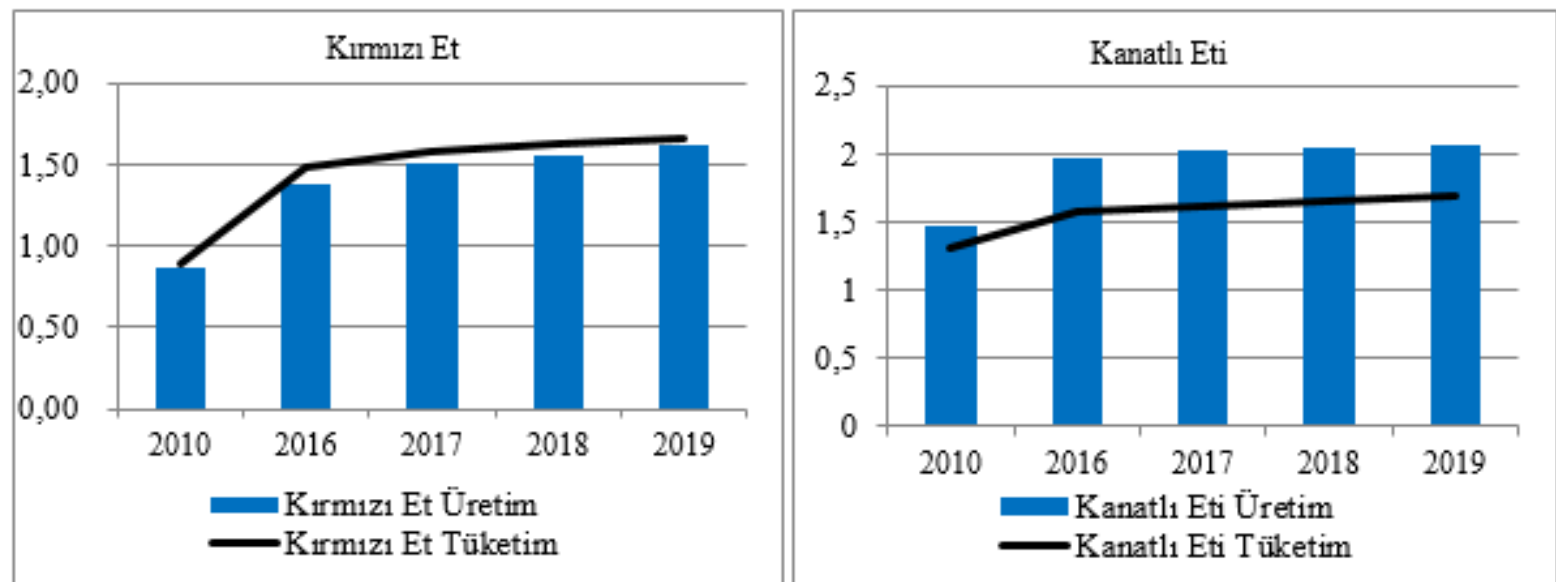

Kaynak: OECD (2021a,b), https://stats.oecd.org/\#

Türkiye'nin et üretiminde bir artış yaşanmasına rağmen üretim miktarı yurtiçi talebi özellikle kırmızı ete olan talebi karşılamaya yetmemiştir (Tablo 2). Buna paralel olarak kırmızı ette yaşanan talep fazlasını karşılayabilmek amacı ile 19902010 yılları arasında yasak olan kırmızı et ithalatına yeniden başlanmıştır. Nitekim, yasaklamanın kaldırıldığı 2010 yılında 42,18 bin ton (domuz eti hariç) kırmızı et ithal edilmiştir. 2019 yllında bu rakam 72,30 bin tona kadar yükselmiştir. Kırmızı et ithalatında yaşanan bu yükseliş devamlılık arz etmemiş, son dönemde uygulanan politikaların ve hayvancılık sektörüne yapılan yatırımların seyrine bağlı olarak yerini düşüşe bırakmıștır (Tarım ve Orman Bakanlığı, 2021).

Türkiye'nin kırmızı et sektöründe talep fazlası yaşanırken kanatlı eti sektöründe arz fazlası yaşanmıştır. Bu durum, kanatlı et ihracatını olumlu yönde etkileyerek son on yıllık periyodda ihracat düzeyini 139,36 bin tondan 466 bin tona yükselmiştir. Türkiye'nin kanatlı eti ihracatının yaklaşık \%96'2'si tavuk etine ait olup, üretilen tavuk etinin \%54,77'si Irak'a (271,17 bin ton) yapılmıştır. İhracat yapılan diğer önemli ülkeler ise sırası ile Çin $(\% 7,5)$ ve Libya'dır $(\% 4,4)$ (Tarımsal Ekonomi ve Politika Geliştirme Enstitüsü [TEPGE], 2021; Trademap, 2021). 
Tablo 2. Türkiye Kırmızı ve Kanatlı Et İhraç ve İthal Yapısı (bin ton)

\begin{tabular}{|c|c|c|c|c|}
\hline \multirow{2}{*}{ Y11 } & \multicolumn{2}{|c|}{ Kirmız Et } & \multicolumn{2}{c|}{ Kanatlı Eti (0207 kodu) } \\
\cline { 2 - 5 } & İthalat1 & İhracat1 & Ithalat1 & İhracat1 \\
\hline 2010 & 42,18 & 10,23 & 6,26 & 139,36 \\
\hline 2016 & 106,41 & 9,41 & 4,46 & 319,06 \\
\hline 2017 & 79,60 & 12,01 & 3,51 & 412,55 \\
\hline 2018 & 76,86 & 12,22 & 3,53 & 466,01 \\
\hline 2019 & 72,30 & 12,59 & 3,5 & 495,04 \\
\hline
\end{tabular}

Kaynak: (OECD, 2021c) https://stats.oecd.org/\# ve (Trademap, 2021).

\section{LİTERATÜR}

Ulusal ve uluslararası alan yazın incelendiğinde; birçok çalışmanın sektörel yoğunlaşma düzeyini ve piyasa rekabet yapısını ele aldığı ve çalışmaların analiz edilen sektör ve kullanılan yöntem bakımından farklılaştığı görülmektedir. Sektörel yoğunlaşmanın ve pazar gücünün analiz edildiği bir kısım ampirik çalışmada panel veri, eşanlı denklem sistemi ile tek denklem yöntemlerinin diğer bir kısım çalışmada ise yoğunlaşma indekslerinin kullanıldı̆̆ Literatür etin işlenmesi ve saklanması sektörü boyutundan incelendiğinde; sektörün yoğunlaşma düzeyini ve piyasa yapısını ele alan bir çalışmanın bulunmadığı, et sektörünün endüstriyel rekabet gücü (Halis ve Bilgin, 2015), kırmızı et sektörünün rekabet politikası (Ünlüsoy, İnce, ve Güler, 2010) ile et ürünleri sektörünün pazar yapısı ve pazar gücü (Önder, 2018) konularının incelendiği görülmektedir.

Araștırma konusu ile doğrudan ilişkili olmamakla birlikte farklı sektörlere ait yoğunlaşma düzeyini ve rekabet yapısını ela alan çalışmaların bazıları aşağıda yer alan Tablo 3'te özetlenmiştir.

Tablo 3. Literatürde Yoğunlaşmayı Analiz Eden Çalışmalar

\begin{tabular}{|c|c|c|}
\hline Yazar & Kapsam & Yöntem \\
\hline Erlat (1991) & $\begin{array}{l}\text { 1970-1990 yıllarına ait veriler kullanılarak; Dokuma, Cam, } \\
\text { Kimya, Seramik, Demir Çelik sektörlerinin ihracat yapısı } \\
\text { incelenmiştir. Yoğunlaşma indekslerinin kullanıldığı } \\
\text { çalışmada, araştırma konusu sektörlerin ortanın üstünde bir } \\
\text { yoğunlaşma düzeyine sahip olduğu sonucuna ulaşılmıştır. }\end{array}$ & $\begin{array}{l}\text { Hirschman-Herfindahl, } \\
\text { Rosenbluth ve } \\
\text { Entropi İndeksi }\end{array}$ \\
\hline $\begin{array}{c}\text { Aktaş ve } \\
\text { Yurdakul (2001) }\end{array}$ & $\begin{array}{l}\text { 1985-1997 verileri kullanılarak Türkiye ve dünya genelinde } \\
\text { un piyasasına ait yoğunlaşma analizi incelenmiştir. Analiz } \\
\text { sonucunda sektöre yönelik yoğunlaşma düzeyinin düşük } \\
\text { olduğu sonucuna ulaşılmıştır. }\end{array}$ & $\begin{array}{c}\text { N-Firma ve Herfindahl } \\
\text { Hirschman İndeksi }\end{array}$ \\
\hline Polat (2007) & $\begin{array}{l}\text { Menkul Kıymetler Borsası’na (İMKB) ait veriler kullanılarak } \\
\text { Türk çimento sektörünün piyasa yapısı 2001-2005 dönemi } \\
\text { için analiz edilmiş olup, N-firma yoğunlaşma sonuçlarına } \\
\text { göre piyasanın oligopol ile monopolcü rekabet piyasası } \\
\text { arasında yer aldığı; HH analizine göre ise sektörün rekabetçi } \\
\text { bir yapıya sahip olduğu sonucuna ulaşılmıştır. }\end{array}$ & $\begin{array}{l}\text { N-Firma ile Herfindahl } \\
\text { Hirschman İndeksi }\end{array}$ \\
\hline Yildiz (2012) & $\begin{array}{l}\text { Çalışmada, geniş bant internet ile Türk telekomünikasyon } \\
\text { hizmet sektörlerinin pazar yoğunlaşma düzeyi incelenmiştir. } \\
2000 \text { ve sonrası dönem verilerinin kullanıldığı çalışmada; her }\end{array}$ & HH indeksi \\
\hline
\end{tabular}




\begin{tabular}{|c|c|c|}
\hline & $\begin{array}{c}\text { iki sektörün yoğunlaşmış oligopol yapısına sahip olduğu ve } \\
\text { sektörlerdeki rekabet düzeyinin düşük olduğu sonucuna } \\
\text { ulaşılmıştır. }\end{array}$ & \\
\hline $\begin{array}{l}\text { Akardeniz ve Kıraç } \\
\qquad(2015)\end{array}$ & $\begin{array}{l}\text { Çalışmada, Gaziantep teknik tekstil sektörünü ele almış ve } \\
\text { sektörün rekabet ve yoğunlaşma düzeyleri CR-4 ve HH } \\
\text { indeksleri ile incelenmiştir. CR-4 yoğunlaşma indeksi ve HH } \\
\text { indeksi analiz sonuçlarına göre sırası ile sektörün } \\
\text { oligopolistik bir yapı sergilediği ve sektörün kuvvetli oligopol } \\
\text { yapıya sahip olduğu sonuçlarına ulaşılmıştır. }\end{array}$ & $\begin{array}{c}\mathrm{N} \text { firma yoğunlaşma } \\
\text { oranı, HH indeksi }\end{array}$ \\
\hline Kaynak (2016) & $\begin{array}{l}\text { 2005-2015 yıllarına ait veriler ışığında, Türk ilaç sanayinin } \\
\text { yoğunlaşma düzeyi ve piyasa yapısı incelenmiştir. Yapılan } \\
\text { analiz sonucunda; yerli ve yabancı firmaların ayrı ayrı } \\
\text { incelendiği takdirde sektörde yoğunlaşma düzeyinin yüksek } \\
\text { olduğu, sektör genel olarak incelendiğinde ise sonucun } \\
\text { değiştiği ve yoğunlaşmanın aynı seviyede yüksek olmadığı } \\
\text { sonucuna ulaşılmıştır. }\end{array}$ & $\begin{array}{l}\text { N-Firma ve Herfindahl } \\
\text { Hirschman İndeksi }\end{array}$ \\
\hline $\begin{array}{l}\text { Kiracı, Yaşar, } \\
\text { Kayhan ve } \\
\text { Ustaömer (2017) }\end{array}$ & $\begin{array}{l}\text { Türkiye’nin en büyük beş havaalanının, 2012-2015 yıllarına } \\
\text { ait yolcu ve kargo miktarları kullanılarak pazar yapısı ve } \\
\text { piyasa yoğunlaşma düzeyi incelenmiştir. Yapılan analizler } \\
\text { neticesinde sektörün rekabetten uzak olduğu sonucuna } \\
\text { ulaşılmıştır. }\end{array}$ & $\begin{array}{c}\text { N-firma ve } \\
\text { Herfindahl-Hirschman } \\
\text { Endeksi }\end{array}$ \\
\hline $\begin{array}{l}\text { Ildırar ve Kıral } \\
\qquad(2018)\end{array}$ & $\begin{array}{l}\text { Hafif ticari araç sektörünün incelendiği çalışmada, 2004-2017 } \\
\text { yıllarına ait veriler kullanılmış ve sektörün yoğunlaşma } \\
\text { düzeyi analiz edilmiştir. Yapılan analiz sonucunda, binek ve } \\
\text { hafif ticari araç piyasasında; yerli araçlarda yoğunlaşma } \\
\text { düzeyinin yüksek, ithal araçlarda ise düşük olduğu sonucuna } \\
\text { ulaşılmıştır. }\end{array}$ & $\begin{array}{l}\text { N-firma ve Herfindahl- } \\
\text { Hirschman endeksleri }\end{array}$ \\
\hline $\begin{array}{l}\text { Ediz ve Önder } \\
\text { (2019) }\end{array}$ & $\begin{array}{l}\text { ISO tarafından yayınlanan ilk } 1000 \text { sanayi kuruluşu içerisinde } \\
\text { yer alan içecek imalatı sektörünün yoğunlaşma düzeyi 2006- } \\
2016 \text { dönem verilerinden yararlanılarak analiz edilmiştir. } \\
\text { Analiz sonucunda ilgili sektörün oligopolistik bir yapıya } \\
\text { sahip olduğu tespit edilmiştir. }\end{array}$ & $\begin{array}{l}\text { N-firma, Hall-Tideman, } \\
\text { Herfindahl-Hirschman, } \\
\text { Kapsamlı Yoğunlaşma, } \\
\text { Entropi, ve Rosenbluth } \\
\text { Endeksleri }\end{array}$ \\
\hline $\begin{array}{l}\text { Serel ve Akşehirli } \\
\qquad(2020)\end{array}$ & $\begin{array}{l}\text { Türkiye Bankacılık sektörüne ait piyasa yoğunlaşma analizi, } \\
\text { 1999-2019 yıllarına ait yıllık veriler kullanılarak analiz } \\
\text { edilmiştir. Analiz bulgularına göre, sektörün } 2001 \text { yılında } \\
\text { güçlü oligopol yapısına sahip olduğu; diğer yıllarda ise zayıf } \\
\text { oligopol yapısına sahip olduğu sonucuna ulaşılmıştır. }\end{array}$ & $\begin{array}{l}\text { K-banka ve Herfindahl- } \\
\text { Hirschman endeksleri }\end{array}$ \\
\hline
\end{tabular}

Kaynak: Yazarlar tarafından oluşturulmuştur. 


\section{VERİ SETI VE YÖNTEM}

Gıda ürünleri imalatı sektöründe yer alan "Etin işlenmesi ve saklanması ile et ürünlerinin imalatı" alt sektörü yoğunlaşma düzeyinin incelendiği çalışmada, İstanbul Sanayi Odası (ISO) tarafından yayınlanan birinci ve ikinci en büyük 500 Büyük Sanayi Kuruluşu verilerinden yararlanılmıştır. Analizde, firmaların 2012-2019 dönemine ait yıllık net satış rakamları kullanılmıştır. Analize dahil edilecek firmaların belirlenmesinde; Avrupa Topluluğu Ekonomik Faaliyetlerin İstatistiki Sinıflaması'na (NACE Rev.2) ait 10.11, 10.12 ve 10.13 kodlarından yararlanılmıştır.

Sektörün piyasa yapısında; firma sayısı, piyasaya giriş koşulları, ölçek ekonomileri, ürün farklılaşması ve ekonomik büyüme gibi unsurlar etkili olmaktadır (Bain, 1968, s. 210) (Davut, 2002, s. 219). Piyasa yapısı bu faktörlerin yanı sıra piyasaya girişi düzenleyen yasal düzenlemelerden, reklamlardan ve firmaların sahip olduğu patent ve ayrıcalıklardan da etkilenmektedir. Tüm bu faktörlerle birlikte sektörün piyasa yapısını ortaya koyabilmek için kullanılan en yaygın ölçüt piyasa yoğunlaşma yöntemidir.

Yoğunlaşma, sektördeki alıcılar veya satıcılar göz önünde bulundurularak incelenmektedir. Ancak piyasada bulunan alıcıların sayıca çok olması analizi güçleştirmektedir. $\mathrm{Bu}$ nedenle yaygın olarak sektörde faaliyet gösteren satıcılar dikkate alınmaktadır (Koch, 1980: 172).

$$
C R_{k}=\sum_{i=1}^{n} S_{i} \quad i=1,2, \ldots, n
$$

İlgili eşitlikteki; CR_k, "k" sayıdaki firmanın piyasa yoğunlaşma oranını, S_i, i'ninci firmanın sektördeki pazar payını ve $\mathrm{n}$ ise sektörde faaliyet gösteren firma sayısını ifade etmektedir. "k" firma yoğunlaşma indeksi çoğunlukla 4, 8 ve 25 firma için hesaplanmaktadır ve indeks sıfır ile bir arasında değerler almaktadır. İndeks değerinin sıfıra yaklaşması sektörde düşük düzeyde

$$
H H=\sum_{i=1}^{n} S_{i}^{2} \quad i=1,2, \ldots, n
$$

Satıcılar için yoğunlaşma; piyasa ve toplam yoğunlaşma olmak üzere iki ana başlıkta gerçekleștirilmektedir. Toplam yoğunlaşma kavramı; piyasada faaliyet gösteren tüm firmaları göz önünde bulundururken piyasa yoğunlaşması; piyasada faaliyet gösteren lider firmaları dikkate almaktadır (Device, Jones, Lee ve Tyson, 1974: 83).

Yoğunlaşmanın ölçümü hususunda iktisat teorisinde netlik olmamakla birlikte firma yoğunlaşmasını hesaplamak için çeşitli yoğunlaşma ölçütleri geliştirilmiştir. Bu ölçütler; göreli ve mutlak olmak üzere iki ana kategoride ele alınmaktadır (Detaylı bilgi için bkz. Pickering, 1974). Göreli yoğunlaşma ölçütü; sektörde faaliyet gösteren firmaların büyüklük dağılımındaki eşitsizliği dikkate alırken mutlak yoğunlaşma ölçütü ise sektörde faaliyet gösteren az sayıda ve büyük firmaların satışlarını baz almakta ve firmaların satışlarını hangi oranda ve nasıl kontrol altında tutukları hususuyla ilgilenmektedir (Utton, 1970: 35).

Yoğunlaşmayı ölçmek için literatürde birçok indeks geliştirilmiş olmasına rağmen ampirik analizlerde yaygın olarak; (i) "k" firma yoğunlaşma (CR_k), (ii) Herfindahl-Hirchman (HH) (iii) Entropi (E) ve (iii) Kapsamlı Yoğunlaşma (CC) indeksleri kullanılmaktadır.

$\mathrm{Bu}$ indekslerden "k" firma yoğunlaşma indeksi (C_k) aşağıda yer alan eşitlik kullanılarak hesaplanmaktadır:

yoğunlaşmanın var olduğuna, değerin bire yaklaşması ise yüksek düzeydeki yoğunlaşmanın varlığına işaret etmektedir (TÜIKK, 2021f).

Literatürde yaygın olarak kullanılan HH indeksinin hesaplanmasında aşağıda yer alan eşitlik kullanılmaktadır: 
HH indeksi, sektörde faaliyet gösteren küçük ve büyük tüm firmaları dikkate almaktadır. Dolayısıyla ilgili eşitlikte yer alan $\mathrm{S}_{\mathrm{i}}{ }^{\wedge}{ }^{\wedge} 2$, sektörde faaliyet gösteren tüm firmaların piyasa paylarının karesini ifade etmektedir. HH indeks değeri sıfır ile bir arasında değerler almaktadır. İndeks değerinin sıfıra yaklaşması düşük düzeyde yoğunlaşmayı diğer bir ifade ile yüksek rekabet düzeyini; indeks değerinin bire yaklaşması ise yüksek düzeyde

$$
E=\sum_{i=1}^{n} S_{i} \log \left(1 / S_{i}\right) \quad i=1,2, \ldots, n
$$

Entropi indeksi, sektörde faaliyet gösteren firmaların sayısını, büyüklüklerini ve piyasa paylarındaki eşitsizliği dikkate almaktadır. İndeks, sektörde faaliyet gösteren firmaların sektör paylarını dikkate almaktadır. Entropi indeksi, k firma yoğunlaşma indeksi gibi sıfır ile bir arasında değerler almaktadır. Ancak bu indeks ters yoğunluk ölçütüdür ve indeks değeri sıfıra yaklaştıkça sektörün yüksek düzeyde yoğunlaşmaya sahip olduğunu ifade etmektedir.

$$
C C=S_{1}+\sum_{i=2}^{n} S_{i}^{2}\left(2-S_{i}\right)
$$

Eşitlikte; S_1 sektördeki en büyük firmanın piyasa payı ile diğer firmaların piyasa paylarının ağırlıklı toplamını vermektedir. İndeks, monopol piyasa durumunda bir değerini, eşit büyüklükte ve çok sayıda firmanın bulunduğu durumda ise sıfır değerini almaktadır (Goodarzi ve Shafiee, 2012). yoğunlaşmayı (düşük rekabeti) ifade etmektedir (Kalkan, 2004; Matsumoto, Merlone, ve Szidarovszky, 2012)

HH indeksi gibi sektörde faaliyet gösteren tüm küçük ve büyük firmaları göz önünde bulunduran bir diğer yoğunlaşma yaklaşımı ise Entropi indeksidir. $\mathrm{Bu}$ indeks aşağıda sunulan eșitlik yardımı ile hesaplanmaktadır:

Sektördeki firmaların pazar büyüklüğünü ve pazar büyüklügünün dağılımını analiz eden bir diğer indeks ise Kapsamlı Yoğunlaşma (CC) indeksidir. İndeksin temeli HH'ye dayanmasına rağmen CC indeksi daha kapsamlıdır. İndeksin kapsamlı olarak nitelendirilmesinde; sektörde faaliyet gösteren firmaların sadece pazar paylarının değil, paylar arasındaki yapının da incelenmesi bulunmaktadır. İndeks aşağıdaki eşitlikteki gibi ifade edilmektedir (Horvarth, 1970; Hexter ve Snow, 1970):

\section{ANALİZ BULGULARI}

Kırmızı ve kanatlı et sektöründe faaliyet gösteren firmaların yoğunlașma düzeyleri, CR_k, HH, CC ve Entropi indeksleri kullanılarak hesaplanmıștır. Sonuçlar Tablo 4'te sunulmuştur.

Tablo 4. Kırmızı Et ile Kanatlı Eti İmalatı Sektörüne Ait Yoğunlaşma Oranları

\begin{tabular}{|c|c|c|c|c|c|}
\hline Yıllar & Firma Sayısi & CR4 & HH & Entropi & CC \\
\hline 2012 & 96 & 0,176477 & 0,18939 & 0,559783 & 0,067941 \\
\hline 2013 & 97 & 0,169149 & 0,18837 & 0,559747 & 0,069797 \\
\hline 2014 & 100 & 0,158833 & 0,17483 & 0,550249 & 0,067374 \\
\hline 2015 & 103 & 0,159843 & 0,16463 & 0,542002 & 0,068958 \\
\hline 2016 & 95 & 0,169933 & 0,18715 & 0,558618 & 0,074113 \\
\hline 2017 & 84 & 0,179999 & 0,20172 & 0,571182 & 0,0741 \\
\hline 2018 & 84 & 0,165858 & 0,18827 & 0,563018 & 0,074568 \\
\hline 2019 & 90 & 0,161941 & 0,169 & 0,544838 & 0,081399 \\
\hline
\end{tabular}

Kaynak: ISO verileri kullanılarak yazarlar tarafından hesaplanmıştır. 
Tablo 3'te verilen yoğunlaşma indeksi analiz sonuçları incelendiğinde; etin işlenmesi ve saklanması sektöründe faaliyette bulunan en büyük ilk dört firmanın yoğunlaşma indeksi (CR4) değerinin \%15 - \%18 bandında hareket ettiği görülmektedir. İlk dört firmanın yoğunlaşma indeksi değerleri sekiz yılık dönemde artışlar ve azalışlar kaydetse de süreç boyunca \%30 seviyesinin altında seyretmektedir. Dolayısıyla, sektöre ait CR4 indeks değerleri, TÜİK (2021f) kapsaminca hesaplanan yoğunlaşma indeks değerleri baz alınarak değerlendirildiğinde; sektörün düșük düzeyde firma yoğunlașma düzeyine sahip olduğu sonucuna ulaşılmaktadır. Benzer sonuçlar HH yoğunlaşma indeksi için de geçerli olup, indeks değeri 2017 yılında en yüksek düzeye (yaklașık 0,202) ulașmıș ancak takip eden yıllarda tekrar eski düzeyine inmiștir. Diğer bir ifade ile indeks değeri analize dahil edilen tüm yıllar için 30'un altında yer almaktadır. Dolayısıyla, indeks sonuçları sektördeki firma yoğunlaşma düzeyinin düşük olduğunu ve sektörün yüksek rekabetçi bir piyasa yapısında faaliyet gösterdiğini ifade etmektedir. Entropi ve CC indeksleri de aynı şekilde etin işlenmesi ve saklanması sektörünün düşük yoğunlaşmaya sahip olduğunu ortaya koymaktadır.

\section{SONUÇ VE DEĞERLENDİRME}

Makalede, ISO tarafından her yıl açıklanan birinci ve ikinci 500 firma içerisinde bulunan, etin işlenmesi ve saklanması sektöründe faaliyet gösteren firmaların 2012-2019 yıllarına ait net satış rakamları incelenerek bu piyasada faaliyette bulunan firmaların yoğunlaşma düzeyleri CR4, HH, CC ve Entropi indeksleri kullanılarak analizi edilmiștir. Analizde kullanılan tüm yoğunlaşma indeksi sonuçlarına göre et ve işlenmiş et sektörü piyasasında faaliyet gösteren firmaların yoğunlaşma düzeyinin düşük olduğu ve piyasanın rekabetçi bir karakter ortaya koyduğu görülmektedir. Buna göre 2012-2019 yılları arasında yoğunlaşma oranında iniş çıkışlı bir görüntü ortaya konulsa da söz konusu oranın dar bir bantta seyrettiği söylenebilir. Başka bir ifade ile sektör tam rekabete yakın bir monopolcü rekabet piyasa özelliği göstermektedir. Nitekim firmalar yüksek rekabet ortamında ürün farklılaştırma yöntemini tercih etmekte ve salam, sosis, sucuk, pastırma gibi ürün çeşitlendirmesine gitmektedir. Bu durum, et ve işlenmiş et sektörünün köklü bir sektör olmasına rağmen cumhuriyetin ilk yıllarında devlet tekelinde olması daha sonra özel sektör faaliyetlerine izin verilse dahi yerel düzeyden ulusal düzeye çıkmakta zorlanan çok sayıda firmayı barındırması, kar oranlarının sınırlı olması ve üretim maliyetlerinin yüksekliği gibi nedenlerden dolayı az yoğunluklu bir piyasa yapısına sahiptir. Piyasa yoğunlaşma oranının düşük seviyelerde olmasının bir diğer nedeni de devlet tarafından sağlanan teşvikler ve üretimin teşvik edilmesidir. İnsan sağlığı için çok önemli bir yere sahip olan et ve et ürünleri her dönem gıda sektöründe üretim yapan firmalar için cazip bir alan olarak karşımıza çıkmaktadır. 


\section{KAYNAKÇA}

Akardeniz, E., ve Kıraç, F. (2015). "Rekabet ve Yoğunlaşma Düzeyinin Ölçülmesi: Gaziantep Teknik Tekstiller Piyasası". Akademik Sosyal Araştırmalar Dergisi, 3(10): 451-472.

Aktaş, E., ve Yurdakul, O. (2001). "Türkiye'de Un Sanayi Sektörünün Analizi". Çukurova Üniversitesi Sosyal Bilimler Enstitüsü Dergisi, 8(8): 261-274.

Bölgesel Çevre Merkezi [REC]. (2016, Temmuz). https://rec.org.tr/wp-

content/uploads/2016/11/et_urunleri_rehberi.pd f, (05.05.2021)

Device, P., Jones, R., Lee, N., ve Tyson, W. (1974). "An Introduction to Industrial Economics". London: George Allen\&Unwin Ltd.

Ediz , Y. ve Önder, K. (2019). "İçecek İmalatı Sektörünün Piyasa Yapısı ve Yoğunlaşma Oranı: Türkiye'nin İlk 1000 Sanayi Kuruluşu Üzerine Bir Uygulama", Dumlupınar Üniversitesi Sosyal Bilimler Dergisi, 60: 25-40.

Erlat, G. (1991). İhracat ve Endüstriyel Yoğunlaşma Arasındaki İlişkinin İmalat Sanayiinden Seçilmiş Bazı Sektörler Açısından İncelenmesi, https://docplayer.biz.tr/29794447-Ihracat-veendustriyel-yogunlasma-arasindaki-iliskininimalat-sanayiinden-secilmis-bazi-sektorleracisindan-incelenmesi.html, (05.05.2021)

FAO. (2021a). Crops and livestock products. http://www.fao.org/faostat/en/\#data/QCL, (10.05.2021)

FAO. (2021b). Livestock Primary. Production. http://www.fao.org/faostat/en/\#data/QL, (10.05.2021)

Goodarzi , A., ve Shafiee, A. (2012). "Market Structure in Iran's Banking Sector: An Application of Multilevel Models", Iranian Journal of Economic Research, 17(50): 43-64.

Halis, M. ve Bilgin, N. (2015). "Endüstriyel Rekabet Gücü ve Kümelenme Potansiyeli İlișkisi: Bişkek Kırmızı Et Sektöründe Bir Araştırma". Kastamonu Üniversitesi İktisadi ve İdari Bilimler Fakültesi Dergisi. 5(3), 66-84.
Hexter, J. ve Snow, J. (1970). "An Entropy Measure of Relative Aggregate Concentration", Southern Economic Journal, 239-243.

Horvarth, J. (1970). "Suggestion For A Comprehensive Measure of Concentration", Southern Economic Journal, 36: 446-452.

Ildırar, M., ve Kıral, E. (2018). "Piyasa Yapısı Ve Yoğunlaşma: Türk Otomotiv Sektörü Üzerine Bir Analiz", Bolu Abant İzzet Baysal Üniversitesi Sosyal Bilimler Enstitüsü Dergisi, 18(1): 93-117.

Kalkan, E. (2004). Yatay Birleşmelerin İncelenmesinde İktisadi Tekniklerin Kullanılması, Rekabet Kurumu Uzmanlı Tezi, http://www.rekabet.gov.tr/File/?path=RO0T\%2F 1\%2FDocuments\%2FUzmanl\%25c4\%25b1k\%2B Tezi\%2Ftez64.pdf, (15.04.2021).

Kaynak, S. (2016). "Türk İlaç Sektörünün Rekabet Yapısı ve Yoğunlaşma Analizi", Çankırı Karatekin Üniversitesi İktisadi ve İdari Bilimler Fakültesi Dergisi, 6(2): 49-66.

Kaynak, S. ve Arı, Y. O. (2011). "Türk Otomotiv Sektöründe Yoğunlaşma: Binek ve Hafif Ticari Araçlar Üzerine Bir Uygulama", Ekonomik Yaklaşım, 22(80), 39-58.

Kiracı, K., Yaşar, M., Kayhan, S. ve Ustaömer, T. (2017). "Türkiye İç Hat Hava Taşımacıllğı Üzerine Herfindahl-Hirshman Endeksi ve CRm Yoğunlaşma Oranı Analizi ile Piyasa Yoğunlaşmasının Tespit Edilmesi", Gaziantep Üniversitesi Sosyal Bilimler Dergisi, 16(3): 687-704.

Koch, J. (1980). "Industrial Organization and Prices", Subsequent Edition, Pearson College Div.

Matsumoto, A., Merlone, U. ve Szidarovszky, F. (2012). "Some Notes on Applying the HerfindahlHirschman Index", Applyed Economics Letters, 19(2): 181-184.

OECD. (2021a). Meat Cunsumption. https://data.oecd.org/agroutput/meatconsumption.htm, (17.06.2021).

OECD. (2021b). OECD-FAO Agricultural Outlook. Human Consumption Per Capita, https://stats.oecd.org/\# (17.06.2021). 
OECD. (2021c). Meat Imports and Exports. https://stats.oecd.org/\#, (17.06.2021).

Ovalı, B.B. (2002). "Türkiyede Et ve Et Ürünleri Sanayinin Durumu ve Sorunları", Gıda ve Yem Bilimi-Tekmolojisi, 1: 36-42.

Önder, K. (2018). "Kırmızı Et ve Et Ürünleri Sanayinin Pazar Gücü: Oligopson Yapısı", A. Acaravcı içinde, Muhasebe, Finans ve İktisat Araştırma Örnekleri (Cilt 1, s. 569-584). Ankara: Nobel Yayıncılık.

Pickering, J. (1974). "Industrial Structure and Market Conduct", Martin Robertson ve Co. Ltd. .

Polat, Ç. (2007). "Yoğunlaşma ve Piyasa Yapısı İlişkisi Çerçevesinde Türk Çimento Sektörünün Yapısal Analizi", Anadolu Üniversitesi Sosyal Bilimler Dergisi, 7(2): 97-116.

Serel, A. ve Akşehirli, N. (2020). "Türk Bankacılık Sektöründe Yoğunlaşma", Yüzüncü Yıl Üniversitesi Sosyal Bilimler Enstitüsü Dergisi, 48, 175-204.

Serhat Kalkınma Ajansı. (2015). TRA2 Bölgesi Kırmızı Et Sektörü Stratejik Analiz. (M. Akkaya, Dü.)

https://www.serka.gov.tr/assets/upload/dosyala r/6a5fa87da6b99b0bd52bfefe40df0bc7.pdf , (17.06.2021).

Tarım ve Orman Bakanlığı. (2012). İllere Göre Kesimhane İşyeri Sayısı Kurulu Kapasite (Baş/Gün). https://www.tarimorman.gov.tr/GKGM/Belgeler/ DB_Gida_Isletmeleri/2012_yili_gida_sanayi_envan teri/1-

5_Onay_Kesimhane_Illere_Gore_Isyeri_Sayi.pdf, (17.06.2021).

Tarım ve Orman Bakanlığı. (2021). Tarım Ürünleri Piyasaları. Dana Eti, https://arastirma.tarimorman.gov.tr/tepge/Belge ler/PDF\%20Tar\%C4\%B1m\%20\%C3\%9Cr\%C3\% BCnleri\%20Piyasalar\%C4\%B1/2020-

Temmuz\%20Tar\%C4\%B1m\%20\%C3\%9Cr\%C3\% BCnleri\%20Raporu/Dana\%20Eti,\%20Temmuz2020,\%20Tar\%C4\%B1m\%20\%C3\%9Cr\%C3\%BC nleri\%20Piyasa\%20Raporu.pdf (17.06.2021).
Tarımsal Ekonomi ve Politika Geliştirme Enstitüsü [TEPGE]. (2021). "Tarım Ürünleri Piyasaları", Tavuk Eti (Ocak 2021). Ankara.

Trademap. (2021). Meat And Edible Offal Of Fowls of The Species Gallus Domesticus, https://www.trademap.org/Country_SelProduct_ TS.aspx?nvpm, (17.06.2021).

TÜİK. (2021a). Kırmızı Et Üretimi, https://biruni.tuik.gov.tr/medas/?kn=79\&locale= tr. (17.04.2021).

TÜİK. (2021b). Kümes Hayvancıllğ̆. Kümes Hayvancıllı̆ Üretimi, https://biruni.tuik.gov.tr/medas/?kn=79\&locale= tr, (17.04.2021).

TÜİK. (2021c). Sanayi. Ekonomik faaliyetlere göre girişim sayısı. https://data.tuik.gov.tr/Kategori/GetKategori?p= sanayi-114\&dil=1 adresinden alınmıștır

TÜİK. (2021d). Sanayi. Ekonomik Faaliyetlere Göre Ciro, https://data.tuik.gov.tr/Kategori/GetKategori?p= sanayi-114\&dil=1, (17.04.2021).

TÜİK. (2021e). Sanayi. Ekonomik Faaliyetlere Göre Çalışanlar Sayısı (NACE Rev. 2), https://data.tuik.gov.tr/Kategori/GetKategori?p= sanayi-114\&dil=1, (17.04.2021).

TÜİK. (2021f). Haber Bülteni 2010. http://www.tuik.gov.tr/PreTablo.do?alt_id=1036 \#, (17.04.2021).

Utton, M. (1970). "Industrial Concentration", Middlesex, England: Penguin Books.

Ünlüsoy, K., İnce, E. ve Güler, F. (2010). "Türkiye Kırmızı Et Sektörü ve Rekabet Politikası", Ankara: Rekabet Kurumu.

Yıldız, F. (2012). "Türkiye'de Mobil Telekomünikasyon ve Genişbant İnternet Hizmetleri Sektöründe Pazar Yoğunlaşmasının Analizi", Süleyman Demirel Üniversitesi Vizyoner Dergisi, 3(6): 47-72. 